\title{
CURSO DIÁRIO E SAZONAL DO POTENCIAL HÍDRICO FOLIAR DE MOGNO EM SISTEMAAGROFLORESTAL ${ }^{1}$
}

Ronaldo Ribeiro de Morais ${ }^{2}$, José Francisco de Carvalho Gonçalves ${ }^{3}$, Joanne Régis Costa ${ }^{2}$ e Glaudecy de Oliveira Ribeiro ${ }^{4}$

\begin{abstract}
RESUMO - Este trabalho objetivou avaliar o curso diário e sazonal do potencial hídrico foliar de mogno (Swietenia macrophylla King) (Meliaceae) em sistema agroflorestal (SAF). O experimento foi realizado em árvores de S. macrophylla plantadas num sistema agroflorestal instalado no Campo Experimental da Embrapa Amazônia Ocidental, Manaus, AM. Avaliou-se o potencial hídrico foliar $\left(\psi_{\mathrm{f}}\right)$ dos cursos diário e sazonal nos anos 2004 e 2005, por meio da utilização de bomba de pressão tipo Scholander. Os resultados indicaram que os valores do $\psi_{\mathrm{f}}$ de $S$. macrophylla, de modo geral, foram superiores no início da manhã e no final da tarde, com redução acentuada ao meio-dia, e que, em relação à sazonalidade de precipitação, as menores taxas foram reportadas para a época menos chuvosa, variando de -26 bar em 2004 para -31 bar em 2005. Verificou-se que o potencial hídrico de Swietenia macrophylla em sistema agroflorestal sofreu reduções significativas em razão dos baixos índices pluviométricos entre junho e outubro de 2005.
\end{abstract}

Palavras-chave: Swietenia macrophylla; Relações hídricas; Amazônia.

\section{DAILY AND SEASONAL LEAF WATER POTENTIAL IN MAHOGANY TREES UNDER AGROFORESTRY SYSTEM}

\begin{abstract}
This study aimed to evaluate the daily and seasonal course of the leaf water potential of Mahogany (Swietenia macrophylla King) (Meliaceae) in an agroforestry system (SAF). The experiment was carried out in Swietenia macrophylla trees planted in agroforestry system installed at the Experimental Field of Embrapa Western Amazon, Manaus-AM. We evaluated the leaf water potential ( $\left.\psi_{f}\right)$ of the daily and seasonal course in 2004 and 2005 through the use of pressure bomb Scholander. The results showed that the values of $\psi_{t}$ of Swietenia macrophylla, generally speaking, were higher in the early morning and late afternoon, with a marked reduction at noon and that, in regard to seasonal precipitation, the lowest rates were reported to the less rainy season, ranging from -26bar in 2004 to -31 bar in 2005. It was found that the water potential of Swietenia macrophylla in agroforestry system was significantly reduced due to the low rainfall between June and October 2005.
\end{abstract}

Keywords: Swietenia macrophylla; Water relations; Amazon.

\footnotetext{
${ }^{1}$ Recebido em 06.06.2014 aceito para publicação em 21.10.2015

${ }^{2}$ Empresa Brasileira de Pesquisa Agropecuária, Embrapa Amazônia Ocidental, Manaus, AM - Brasil. E-mail: E-mail: <ronaldo.morais@embrapa.br>e <joanne.regis@embrapa.br>.

${ }^{3}$ Instituto Nacional de Pesquisas da Amazônia, INPA, Manaus, AM - Brasil. E- mail: <jfc@inpa.gov.br>.

${ }^{4}$ Universidade Luterana do Brasil, ULBRA, Graduado em Biologia, Manaus, AM - Brasil. E-mail: <bio.gor@hotmail.com>.
} 


\section{INTRODUÇÃO}

Na Amazônia, plantios homogêneos de mogno (Swietenia macrophylla) possuem limitação devido a ataques frequentes da lagarta Hypsiphyla grandella Zeller, Lepidoptera (GUIMARÃES NETO et al., 2004; SOUSA et al., 2005). Em razão desse fato, têm-se testado vários sistemas, como plantios em sistemas agroflorestais. Os Sistemas Agroflorestais (SAFs) são modelos de exploração de espécies florestais com cultivos agrícolas ou animais que vêm sendo testado, como uma forma alternativa nos trópicos úmidos, conciliando a produção de alimentos com a manutenção da fertilidade dos solos (YARED; CARPANEZZI, 1981; BRIENZA et al., 1983). Contudo, ainda hoje pouco se conhece sobre a tecnologia de plantio dessa espécie em sistema agroflorestal, bem como as suas respostas físiológicas e o estado hídrico foliar sob diferentes condições de regimes pluviométricos em condições de campo.

Entre os parâmetros utilizados para a caracterização do comportamento das relações hídricas de plantas e seu estado hídrico, o potencial hídrico foliar $\left(\psi_{\mathrm{f}}\right)$ fornece informações sobre o estado energético da folha e os gradientes que explicam o fluxo no sistema soloplanta-atmosfera e a eficiência no uso da água (KOZLOWSKI, 1968; LARCHER, 2004).

Os processos fisiológicos e metabólicos relacionados ao crescimento e à produtividade das espécies são fortemente influenciados pela disponibilidade de água na planta. Essa disponibilidade afeta o crescimento das plantas, entre outros fatores, por ter grande importância na turgescência celular (KLEINING; SITTE, 1992; DÜNISCH etal., 2003), biossíntese de carboidratos (HOLL, 1985; LANGENFELD-HEYSER, 1987) e transporte de substâncias (VIGOUROUX et al., 1989).

Associados aos estudos do estado hídrico foliar, também são importantes os do regime de água do solo, em florestas ou plantios, ou da variação anual da água do solo nesses ambientes, nas mais diversas situações, uma vez que alguns trabalhos (KOZLOWSKI, 1968; DÜNISCH et al., 1999b; MIRANDA et al., 2011) têm demonstrado que o crescimento da floresta ou de plantios é mais dependente da umidade do solo do que qualquer outro fator do ambiente. Os conhecimentos de como as plantas utilizam a água do solo são importantes no estabelecimento de estratégias eficazes de manejo (SILVA et al., 2003; GOMES; PRADO, 2007; SWAEF et al., 2009).
Com o declínio da disponibilidade hídrica dos solos, o potencial de água da folha também diminui, levando à perda da turgescência e ao fechamento estomático e, como consequência, a menor assimilação de $\mathrm{CO}_{2}$, reduzindo a taxa de produção primária de fotoassimilados (SILVA et al., 2003).

Por isso, devido à escassez de estudos envolvendo as relações hídricas de árvores de mogno em sistemas agroflorestais, este trabalho teve como objetivo caracterizar o curso diário e sazonal do potencial hídrico foliar da espécie.

\section{MATERIAL E MÉTODOS}

O estudo foi realizado na Estação Experimental da Embrapa Amazônia Ocidental, situada no Distrito Agropecuário da SUFRAMA, ao Norte de Manaus, no km 54 da BR-174 (Manaus - Boa Vista) nos anos 2004 e 2005. O Campo Experimental está localizado entre as coordenadas geográficas $2^{\circ} 31^{\prime}$ a $2^{\circ} 32^{\prime}$ 'S e $60^{\circ} 01^{\prime}$ a $60^{\circ} 02^{\prime}$ W. O clima local, conforme a classificação de Köppen, é do tipo como $A f$, com clima tropical úmido ou superúmido, sem estação seca, com total das chuvas do mês mais seco superior a $60 \mathrm{~mm}$, com precipitações maiores de março a agosto, ultrapassando o total de $1.500 \mathrm{~mm}$ anuais (ALVARES et al., 2014).

O solo da área corresponde a um Latossolo Amarelo distrófico (TEIXEIRA; BASTOS, 1989), de textura muito argilosa, onde são encontradas limitações de fertilidade, acidez elevada, baixa capacidade de troca de cátions, deficiências de fósforo, nitrogênio, cálcio e magnésio (MACKERROW, 1992; FERNANDES; MATTOS, 1997).

O estudo foi realizado com árvores de $S$. macrophylla de aproximadamente 12 anos e média de altura total e diâmetro à altura do peito (DAP) de 13 $\mathrm{m}$ e $20 \mathrm{~cm}$, respectivamente, plantadas num sistema agroflorestal "multiestrato" constituído por: guaraná (Paullinia cupana) cupuaçu (Theobroma grandiflorum), castanha-do-brasil (Bertholletia excelsa), mogno (Swietenia macrophylla King), capoeirão (Colubrina glandulosa), pimenta-do-reino (Piper nigrum) e pelas espécies utilizadas como adubo verde, ingá (Inga edulis) e gliricídia (Gliricia sepium) plantada como cerca viva ao redor de todo o sistema (Figura 1).

O delineamento experimental do sistema foi composto por parcelas de $50 \mathrm{~m}$ x $60 \mathrm{~m}\left(3.000 \mathrm{~m}^{2}\right)$ cada, com três repetições. Em cada parcela, excluindo-se 
a bordadura do sistema, foram selecionadas aleatoriamente cinco árvores de mogno para a realização das avaliações, num total de 15 árvores, sendo em cada árvore analisado o $\psi_{\mathrm{f}}$. em três folhas situadas na parte externa da copa.

As avaliações do potencial hídrico foliar foram realizadas em folhas completamente expandidas situadas na parte externa da copa em horários distintos $(5 \mathrm{~h}$, $8 \mathrm{~h}, 10 \mathrm{~h}, 12 \mathrm{~h}, 14 \mathrm{~h}$ e $16 \mathrm{~h}$ ), por meio da utilização da bomba de pressão tipo Scholander. A partir da observação do comportamento do curso diário do $\psi$, verificaram-se os horários que apresentaram o maior e o menor $\psi_{\mathrm{f}}(5 \mathrm{~h}$ e $12 \mathrm{~h})$ para a comparação entre os períodos distintos de precipitação (chuvoso e seco). Esses dados foram submetidos à análise de variância e as médias, comparadas pelo teste de Tukey a 5\% (SAEG, 2007). Procedeu-se também ao ajuste das curvas do curso diário do $\psi_{\mathrm{f}}$, por meio de equações polinomiais. Os dados climatológicos dos anos 2004 e 2005 foram obtidos na Estação Agroclimatológica da Embrapa Amazônia Ocidental, Manaus, AM, durante os anos 2004 e 2005.

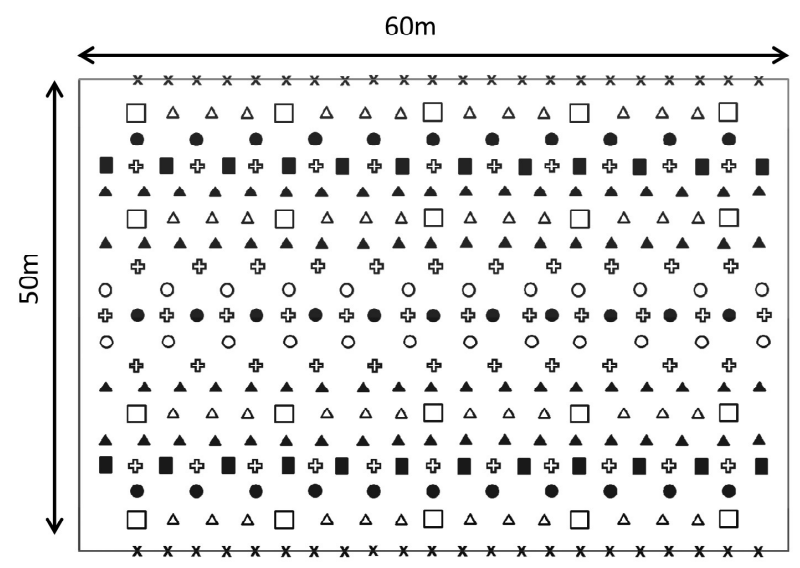

Figura 1 - Croqui do sistema agroflorestal "multiestrato" no Campo Experimental da Embrapa Amazônia Ocidental. Símbolos: Bertholletia excelsa ( $\square$ ); Colubrina glandulosa (ロ); Theobroma grandiflorum

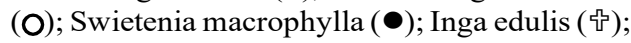
Piper nigrum ( $\mathbf{\Delta})$; Paullinia cupana $(\Delta)$; e Gliricia sepium (X).

Figure 1 - Layout of Agroforestry System "multistrata" at Experimental Field of Embrapa Western Amazon. Symbols: Bertholletia excelsa ( $\square)$; Colubrina glandulosa $(\mathbf{\square})$; Theobroma grandiflorum (O); Swietenia macrophylla $(\bullet)$; Inga edulis (や); Piper nigrum ( $\mathbf{\Delta})$; Paullinia cupana $(\Delta)$; and Gliricia sepium $(X)$

\section{RESULTADOS}

Em relação à caracterização do balanço hídrico da área do estudo, observou-se para o ano 2004 uma precipitação total de $2.667,7 \mathrm{~mm}$, com um excedente reportado para os meses de fevereiro a junho e de setembro a novembro, num total de 939,6 mm. Nos meses de julho e novembro, ocorreu pequena deficiência hídrica, num total de 25,9 mm. Esses dados do balanço hídrico de 2004 encontram-se dentro da normalidade, se comparados ao do balanço hídrico da série histórica (1971-2005)(Tabela 1). Contrastando com o balanço hídrico de 2004, o de 2005, além de mostrar grande diferença na precipitação total $(3.211,6 \mathrm{~mm})$ em comparação com a série histórica $(2.586,9 \mathrm{~mm})$, contrastou com os volumes excedentes de $1.772,0 \mathrm{~mm}$ e de deficiência hídrica em $229,8 \mathrm{~mm}$, reportados para os meses de junho a outubro.

Verificou-se que o comportamento do curso diário do $\psi_{\mathrm{f}}$ de $S$. macrophylla no período chuvoso, tanto em 2004 quanto em 2005, apresentou decréscimo no $\psi_{\mathrm{f}}$ no horário das 5 às $8 \mathrm{~h}$, diminuindo de forma mais acentuada até o meio-dia. A partir desse horário, observou-se que as folhas exibiram acréscimo gradual do $\psi_{\mathrm{f}}$ no decorrer da tarde (Figura 2).

No período seco, o comportamento do ritmo circadiano do $\psi_{\mathrm{f}}$ foi similar ao período chuvoso. No entanto, houve decréscimo maior do $\psi_{\mathrm{f}}$ das 5 às $8 \mathrm{~h}$, para $S$. macrophylla no ano 2005. Adicionalmente, observou-se que no período seco do ano 2005 os valores de $\psi_{\mathrm{f}}$ em relação ao curso diário foram inferiores aos encontrados no período seco do ano 2004, em todos os horários (Figura 2).

Foram ajustadas as equações polinomiais para estimar o comportamento biológico do efeito do ritmo circadiano sobre o $\psi_{\mathrm{f}}$ das folhas de $S$. macrophylla, nos períodos chuvosos e secos, de ambos os anos. No ano 2004, as equações $y=0,072 x^{3}-2,041 x^{2}+15,801 x$ $-37,672$, com $R^{2}=0,80, y=0,092 x^{3}-2,659 x^{2}+21,394 x$ $-55,618$, com $\mathrm{R}^{2}=0,88$, foram ajustadas para os períodos seco e chuvoso, respectivamente. No ano 2005 , as equações $\mathrm{y}=0,073 \mathrm{x}^{3}-1,962 \mathrm{x}^{2}+13,509 \mathrm{x}-31,098$, com $R^{2}=0,78$ e $y=0,100 x^{3}-2,8143 x^{2}+22,198 x-63,274$, com $\mathrm{R}^{2}=0,96$, foram as que melhor se ajustaram para estimar o comportamento do $\psi_{\mathrm{f}}$ dos períodos seco e chuvoso, respectivamente.

Os resultados indicaram que em 2004 e 2005, tanto no horário de antemanhã quanto ao de meio-dia, como 
Tabela 1 - Balanço hídrico com base nos parâmetros climatológicos dos anos 2004 e 2005 e na capacidade máxima de água disponível no solo (CAD) de $50 \mathrm{~mm}$, medidos na estação agroclimatológica da Embrapa Amazônia Ocidental, Manaus.

Table 1 - Water balance based on climatological parameters of the years 2004 and 2005 and the maximum capacity of water available in soil (CAD) of $50 \mathrm{~mm}$, measured in the agrometeorological station of Embrapa Western Amazon, Manaus.

\begin{tabular}{|c|c|c|c|c|c|c|}
\hline \multicolumn{7}{|c|}{ Balanço hídrico (série histórica 1971-2005) } \\
\hline Meses & $\begin{array}{l}\text { Temperatura } \\
\text { média }\left({ }^{\circ} \mathrm{C}\right)\end{array}$ & $\begin{array}{l}\text { Precipitação } \\
(\mathrm{mm})\end{array}$ & $\begin{array}{l}\text { Armazenamento } \\
(\mathrm{mm})\end{array}$ & $\begin{array}{l}\text { Evaporação } \\
\text { real }(\mathrm{mm})\end{array}$ & $\begin{array}{l}\text { Excedente } \\
(\mathrm{mm})\end{array}$ & $\begin{array}{l}\text { Deficiência } \\
(\mathrm{mm})\end{array}$ \\
\hline Janeiro & 25,6 & 258,6 & 50 & 114,7 & 143,9 & 0 \\
\hline Fevereiro & 25,5 & 293,1 & 50 & 105,2 & 187,9 & 0 \\
\hline Março & 25,5 & 318,8 & 50 & 121,1 & 197,6 & 0 \\
\hline Abril & 25,6 & 323,0 & 50 & 122,9 & 200,1 & 0 \\
\hline Maio & 25,8 & 277,0 & 50 & 132,8 & 144,2 & 0 \\
\hline Junho & 25,5 & 166,7 & 50 & 126,4 & 40,2 & 0 \\
\hline Julho & 25,6 & 119,2 & 40,3 & 128,9 & 0 & 1,1 \\
\hline Agosto & 26,1 & 108,5 & 23,1 & 125,7 & 0 & 10,7 \\
\hline Setembro & 26,5 & 126,0 & 18,8 & 130,3 & 0 & 6,0 \\
\hline Outubro & 26,7 & 166,3 & 45,9 & 139,2 & 0 & 0 \\
\hline Novembro & 26,4 & 185,9 & 50 & 125,9 & 55,8 & 0 \\
\hline Dezembro & 25,9 & 244,0 & 50 & 119,8 & 124,2 & 0 \\
\hline Ano & 25,9 & $2.586,9$ & - & $1.492,9$ & $1.093,9$ & 17,8 \\
\hline \multicolumn{7}{|c|}{ Balanço hídrico (ano 2004) } \\
\hline Meses & $\begin{array}{l}\text { Temperatura } \\
\text { média }\left({ }^{\circ} \mathrm{C}\right)\end{array}$ & $\begin{array}{l}\text { Precipitação } \\
(\mathrm{mm})\end{array}$ & $\begin{array}{l}\text { Armazenamento } \\
(\mathrm{mm})\end{array}$ & $\begin{array}{l}\text { Evaporação } \\
\text { real }(\mathrm{mm})\end{array}$ & $\begin{array}{l}\text { Excedente } \\
(\mathrm{mm})\end{array}$ & $\begin{array}{l}\text { Deficiência } \\
\quad(\mathrm{mm})\end{array}$ \\
\hline Janeiro & 27,1 & 163,0 & 34,4 & 136,6 & 0,0 & 0 \\
\hline Fevereiro & 27,2 & 211,0 & 50,0 & 130,9 & 64,5 & 0 \\
\hline Março & 26,7 & 462,8 & 50,0 & 141,7 & 321,1 & 0 \\
\hline Abril & 27,0 & 317,5 & 50,0 & 142,1 & 175,4 & 0 \\
\hline Maio & 26,8 & 291,0 & 50,0 & 150,4 & 140,6 & 0 \\
\hline Junho & 26,6 & 266,4 & 50,0 & 144,5 & 121,9 & 0 \\
\hline Julho & 26,8 & 109,5 & 21,5 & 138,0 & 0,0 & 13,7 \\
\hline Agosto & 26,9 & 158,9 & 31,8 & 148,6 & 0,0 & 0 \\
\hline Setembro & 27,4 & 252,4 & 50,0 & 145,4 & 88,9 & 0 \\
\hline Outubro & 28,1 & 178,5 & 50,0 & 151,3 & 27,2 & 0 \\
\hline Novembro & 28,7 & 105,3 & 22,7 & 132,6 & 0 & 12,2 \\
\hline Dezembro & 27,1 & 151,4 & 38,6 & 135,5 & 0 & 0 \\
\hline Ano & 27,2 & $2.667,7$ & - & $1.697,6$ & 939,6 & 25,9 \\
\hline \multicolumn{7}{|c|}{ Balanço hídrico (ano 2005) } \\
\hline Meses & $\begin{array}{l}\text { Temperatura } \\
\text { média }\left({ }^{\circ} \mathrm{C}\right)\end{array}$ & $\begin{array}{l}\text { Precipitação } \\
(\mathrm{mm})\end{array}$ & $\begin{array}{l}\text { Armazenamento } \\
\qquad(\mathrm{mm})\end{array}$ & $\begin{array}{l}\text { Evaporação } \\
\text { real }(\mathrm{mm})\end{array}$ & $\begin{array}{l}\text { Excedente } \\
(\mathrm{mm})\end{array}$ & $\begin{array}{l}\text { Deficiência } \\
(\mathrm{mm})\end{array}$ \\
\hline Janeiro & 26,3 & 253,7 & 50 & 123,7 & 118,6 & 0 \\
\hline Fevereiro & 26,7 & 370,2 & 50 & 123,7 & 246,5 & 0 \\
\hline Março & 25,6 & 439,1 & 50 & 117,9 & 321,2 & 0 \\
\hline Abril & 26,0 & 445,9 & 50 & 126,2 & 319,7 & 0 \\
\hline Maio & 26,7 & 355,0 & 50 & 150,4 & 204,6 & 0 \\
\hline Junho & 28,5 & 127,4 & 24,2 & 153,2 & 0 & 10,5 \\
\hline Julho & 26,6 & 72,5 & 5,3 & 91,4 & 0 & 57,1 \\
\hline Agosto & 27,4 & 75,2 & 1,1 & 79,4 & 0 & 75,6 \\
\hline Setembro & 27,9 & 122,9 & 0,6 & 123,4 & 0 & 25,0 \\
\hline Outubro & 28,4 & 89,3 & 0,2 & 89,7 & 0 & 61,6 \\
\hline Novembro & 27,3 & 390,9 & 50 & 133,4 & 207,7 & 0 \\
\hline Dezembro & 25,9 & 469,5 & 50 & 115,8 & 353,7 & 0 \\
\hline Ano & 26,9 & $3.211,6$ & - & $1.428,2$ & $1.772,0$ & 229,8 \\
\hline
\end{tabular}

Fonte: adaptado de Couen, (2009 a, b).

Source: adapted from Couen, $(2009 a, b)$.

Revista Árvore, Viçosa-MG, v.39, n.6, p.1103-1110, 2015 
esperado, o $\psi_{\mathrm{f}}$ foi superior no período de maior pluviosidade (chuvoso), em comparação com o de menor pluviosidade (seco) (Tabela 2).

No ano 2004, em relação aos períodos de antemanhã e meio-dia, houve redução de $64 \%$ e $23 \%$ dos valores do $\psi_{\mathrm{f}}$ nos períodos chuvoso e seco, respectivamente. Já no ano 2005 essa redução foi de $56 \%$ e $18 \%$, respectivamente (Tabela 2 ).

\section{DISCUSSÃO}

Como pode ser observado em relação aos dados de precipitação, registrou-se um grande período de

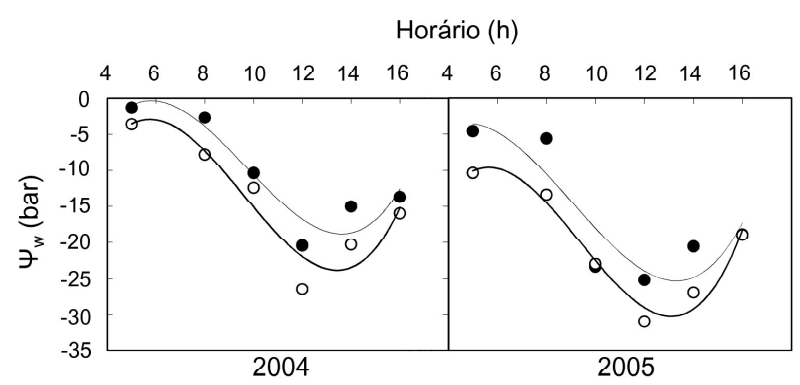

Figura 2 - Curso diário do potencial hídrico de Swietenia macrophylla em sistema agroflorestal em horários e períodos distintos de precipitação: chuvoso $(\bullet)$ e $\operatorname{seco}(0)$, na região de Manaus, durante 2004 e 2005 .

Figure 2-Daily course of water potential of Swietenia macrophylla in distinct agroforestry system schedules and periods of rainfall: Wet $(\bullet)$ and dry $(\mathbf{O})$ in the region of Manaus, in 2004 and 2005.

Tabela 2 - Potencial hídrico de Swietenia macrophylla em sistema agroflorestal, obtido em horários e períodos distintos de precipitação pluviométrica (chuvoso e seco) na região de Manaus, durante os anos 2004 e $2005, n=45$.

Table 2 - Water potential of Swietenia macrophylla in agroforestry system, obtained at different times and periods of precipitation (wet and dry) in the Manaus region during the years 2004 and 2005, $n=45$.

\begin{tabular}{lcc}
\hline & \multicolumn{2}{c}{2004} \\
\hline Chuvoso & Antemanhã $(05: 00 \mathrm{~h})$ & Meio-dia $(12: 00 \mathrm{~h})$ \\
Seco & $-1,30 \mathrm{a}$ & $-20,44 \mathrm{a}$ \\
& $-3,62 \mathrm{~b}$ & $-26,50 \mathrm{~b}$ \\
& & 2005 \\
Chuvoso & Antemanhã $(05: 00 \mathrm{~h})$ & Meio-dia $(12: 00 \mathrm{~h})$ \\
Seco & $-4,60 \mathrm{a}$ & $-25,20 \mathrm{a}$ \\
\hline
\end{tabular}

Médias seguidas pela mesma letra na coluna não diferem estatisticamente, pelo teste de Tukey a $5 \%$. deficiência hídrica no ano 2005, se comparado ao de 2004 e à série histórica (1971-2005). Esse fato foi registrado por Suguio (2008), como uma das maiores secas dos últimos 40 anos. Em 2005, as condições de seca foram intensificadas durante a estação seca até outubro, quando a umidade relativa do ar foi muito menor que o normal, e caracterizou-se por apresentar o menor índice pluviométrico no período menos chuvoso dos últimos 40 anos, ultrapassando períodos como os de 1925-1926, 1968-1969 e 1997-1998 até então considerados como os de menores índices (OLIVEIRA et al., 2012).

Avaliando-se o comportamento do curso diário do $\psi_{\mathrm{f}}$, os resultados indicaram que no horário de antemanhã, como esperado, as folhas de $S$. macrophylla apresentaram maiores valores do $\psi_{\mathrm{f}}$, isso em decorrência do equilíbrio do status hídrico da planta e do solo, uma vez que durante a noite o $\psi_{\mathrm{f}}$ da planta tende a se equilibrar com o potencial de água do solo (SCHMIDHALTER, 1997; ANDRADE et al., 1998; WILLIAMS; ARAÚJO, 2002).

A redução do $\psi_{\mathrm{f}}$ ao meio-dia é um comportamento esperado, pois há a elevação das taxas transpiratórias em razão da elevação da temperatura foliar. Como estratégia, a planta intensifica suas taxas transpiratórias, pois no processo de transpiração ocorre resfriamento foliar. Alguns fatores podem afetar o nível mínimo que o do $\psi_{\mathrm{f}}$ pode atingir durante os horários de transpiração intensa, como fatores genéticos e fatores ambientais (p. ex., pré-aclimatação - a situação de estresse) (COSTA; MARENCO, 2007). O processo de evaporação da molécula da água pelas plantas ocasiona substancial perda de calor e constitui um dos meios mais importantes para regular suas altas temperaturas (TAIZ; ZEIGER, 2004).

Em dias ensolarados e próximos ao meio-dia, é comum as árvores experimentarem um balanço hídrico negativo, pois a absorção de água não compensa as perdas por transpiração (LARCHER, 2004). No caso deste estudo, devido ao fato de as árvores de $S$. macrophylla terem em média $12 \mathrm{~m}$ de altura e grande porte da superfície transpirante, normalmente não estariam sujeitas ao desenvolvimento de déficit hídrico acentuado, em que qualquer distúrbio no seu balanço hídrico deve ser prontamente respondido. Essa redução do potencial hídrico foliar no horário entre 12 h e 14 h ocorre mesmo quando a umidade do solo está próxima da capacidade de campo, pois nesse horário ocorre aumento das taxas

Revista Árvore, Viçosa-MG, v.39, n.6, p.1103-1110, 2015

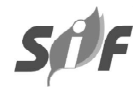


de transpiração devido à alta demanda atmosférica (MEDINA et al., 1999; NOGUEIRA et al., 2000).

No que se refere aos valores inferiores do $\psi_{\mathrm{f}} \mathrm{de}$ $S$. macrophylla no período menos chuvoso, eles podem indicar estratégia de ajuste osmótico utilizada pela planta, com a possível redução no $\psi_{\mathrm{f}}$ foliar para que haja absorção de água mais efetiva e manutenção da turgescência das células no tecido foliar (MARTIN et al., 2004). No ano 2005, os valores do $\psi_{\mathrm{f}}$ foram inferiores aos comparados no ano 2004, independentemente do horário e da época de precipitação. Esse fato pode ter sido consequência dos baixos índices de precipitação no período seco de 2005 (Tabela 1).

Essa redução nos índices pluviométricos pode promover impactos negativos ao crescimento de $S$. macrophylla. Investigações dendrológicas revelam forte influência da disponibilidade de água no solo sobre o crescimento de árvores (COSTER, 1927; WORBES, 1988; VETTER; BOTOSSO, 1989; PUMJUMNONG et al., 1995; DÜNISCH et al., 1999a). Estudos realizados por Dünisch et al. (1999b) evidenciaram que houve grande impacto da disponibilidade de água no desenvolvimento de $S$. macrophylla, em que a formação de faixas de parênquima e dormência cambial foi correlacionada com a redução da disponibilidade de água para as árvores.

De acordo com estudos realizados por Noldt et al. (1999), comparando o sistema radicular de $S$. macrophylla e Carapa guianensis, observou-se que o comprimento e o diâmetro de raízes finas de $S$. macrophylla foram significativamente mais elevados, comparado com as raízes finas de C. guianensis. Isso indicaria elevada eficiência na absorção e transporte hídrico do sistema radicular de árvores de $S$. macrophylla durante períodos secos. Isso corrobora os dados de Lamb (1966), no qual caracteriza a espécie como uma de alta plasticidade genética, dada a sua capacidade de adaptação de sobreviver em diferentes ecótipos, inclusive em condições de déficit hídrico prolongado, com menos de $100 \mathrm{~mm}$ de precipitação por mês em solos rasos e bem drenados. Ecologicamente, é caracterizada com uma espécie que se comporta como heliófita e, com os estômatos presentes, somente na face abaxial das folhas (hispoestomática), sendo considerada espécie pioneira ou espécie sucessional.

\section{CONCLUSÃO}

O baixo índice pluviométrico reportado nos meses de junho a outubro de 2005 afetou negativamente o potencial hídrico foliar apresentado por Swietenia macrophylla em sistema agroflorestal, com redução significativa tanto no horário de antemanhã quanto ao meio-dia.

\section{AGRADECIMENTOS}

À Fundação de Amparo à Pesquisa no Estado do Amazonas (FAPEAM), pelo apoio financeiro e pela concessão da bolsa de pesquisa; ao Instituto Nacional de Pesquisas da Amazônia (INPA), principalmente ao Laboratório de Fisiologia e Bioquímica Vegetal, pelo apoio logístico e pela infraestrutura; ao projeto LBA, pelo apoio logístico; à Embrapa Amazônia Ocidental, em especial aos pesquisadores da equipe responsável, pelos estudos com sistemas agroflorestais, pelo apoio logístico e pela concessão da área de estudo.

\section{REFERÊNCIAS}

ALVARES, C.A.; STAPE, J.L.; SENTELHAS, P.C.; GONCALVES, J.L.M.; SPAROVEK, G. Köppen's climate classification map for Brazil.

Meteorologische Zeitschrift, v.22, n.6, p.711-728, 2014.

ANDRADE, J.L.; MEINZER, F. C.; GOLDSTEIN, G.; HOLBROOK, N. M.; CAVELIER, J.; JACKSON, P.; SILVERA, K. Regulation of the water flux throughout trunks, branches and leaves in trees of a lowland tropical forest. Oecologia, v.115, n.4, p.463-471, 1998.

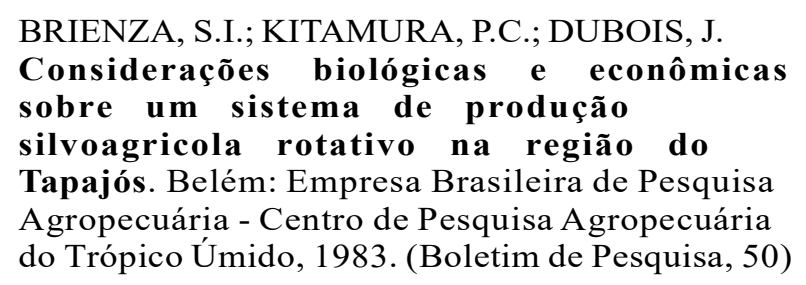

COHEN, A.I. Boletim Agrometeorológico 2004: Estação Agroclimatológica da Embrapa Amazônia Ocidental. Manaus: Embrapa Amazônia Ocidental, 2009a. 27p. (Documentos, 64).

COHEN, A. I. Boletim Agrometeorológico 2005: Estação Agroclimatológica da Embrapa 
Amazônia Ocidental. Manaus: Embrapa Amazônia Ocidental, 2009b. 27 p. (Documentos, 65).

COSTA, G.F.; MARENCO, R.A. Fotossíntese, condutância estomática e potencial hídrico foliar em árvores jovens de andiroba (Carapa guianensis). Acta Amazônica, v.37, n.2, p.229-234, 2007.

COSTER, C. Zur Anatomie und Physiologie der Zuwaschszonen und Jahreringbildung in den Tropen. I. Ann. Jard. Buitenzorg, n. 37 , p.49-161, 1927.

DÜNISCH, O.; BAUCH, J.; SACK, M.; MAILER, $M$. Growth dynamics in wood formation of plantation-grow Swietenia macrophylla King. and Carapa guianensis Aubl. BFH Mitteilungen, v.193, n.1, p.79-96, 1999a.

DÜNISCH, O.; ERBREICH, M.; EILERS, T. Water balance and water potentials of a monoculture and an enrichment plantation of $C$. guianensis Aubl. in the Central Amazon. Forest Ecology and Management, v.172, n.2-3, p.355-367, 2003.

DÜNISCH, O. SCHROTH, G.; MORAIS, R. R.; ERBREICH, M. Water supply of Swietenia macrophylla King and Carapa guianensis Aubl. in three plantation systems. BFH Mitteilungen, v.193, n.1, p.29-45, 1999b.

FERNANDES, E.C.M.; MATTOS, J.C.S.

Agroforestry strategy for alleviating soil chemical constraints to food and fibre production in Amazon. In: SEIDLL, P.R. et al. Plant propagation: principles and practices. 6.ed. New Jersey; Prentice Hall International, 1997. 770p.

GOMES, F.P.; PRADO, C.H.B.A. Ecophysiology of coconut palm under water stress. Brazilian Journal of Plant Physiology, v.19, n.4, p.377-391, 2007.

GUIMARÃES NETO, A.B.; FELFILI, J. N.; SILVA, G. F.; MAZZEI, L.; FAGG, C. W.; NOGUEIRA, P. E. Avaliação do plantio homogêneo de mogno, Swietenia macrophylla King, em comparação com o plantio consorciado com Eucalyptus urophylla $S$. T. Blake, após 40 meses de idade. Revista Árvore, v.28, n.6, p.777-784, 2004.

HOLL, W. Seasonal fluctuation of reserve materials in the trunkwood of spruce (Picea abies
[L.] Karst). Journal Plant Physiology, v.117, p.355-362, 1985.

KLEINING, H.; SITTE, P. Zellbiologie.

Stuttgart: Gustav Fischer Verlag Jena, 1992. 591 p.

KOZLOWSKI, T.T. Water deficits and plant growth. New York: Academic Press, 1968. p.1-21.

LAMB, F.B. Mahogany in tropical America: Its ecology and management. Ann Arbor: University of Michigan Press, 1966. 220p.

LANGENFELD-HEYSER, R. Distribution of leaf assimilates in the stem of Picea abies. Trees, v.1, n.1, p.102-109, 1987.

LARCHER, W. Ecofisiologia vegetal. São

Carlos: Rima, 2004. 531p.

MACKERROW, A.J. Nutrients stocks in abandoned pastures of the Central Amazon Basin prior to and following cutting and burning. 116f. Dissertation (Master's Degree) - North Carolina State University, Raleigh, 1992.

MARTIN, C.E., LIN. T. C.; LIN, K. C.; HSU, C. C.; CHIOU, W. L. Causes and consequences of high osmotic potentials in epiphytic higher plants. Journal of Plant Physiology, v. 161, n.10, p.1119-1124, 2004.

MEDINA, C.L.; MACHADO, E.C.; GOMES, M.M.A. Condutância estomática, transpiração e fotossíntese em laranjeira Valência sob deficiência hídrica. Revista Brasileira de Fisiologia Vegetal, v.11, n.1, p.29-34, 1999.

MIRANDA, L.D.P.; VITÓRIA, A.P.; FUNCH, L.S. Leaf phenology and water potential of five arboreal species in gallery and montane forests in the Chapada Diamantina; Bahia; Brazil.

Environmental and Experimental of Botany, n.70, p.143-150, 2011.

NOGUEIRA, R.J.M.C.; MORAES, J.A.P.V.; BURITY, H.A. Curso diário e sazonal das trocas gasosas e do potencial hídrico foliar em aceroleiras. Pesquisa Agropecuária Brasileira, v.35, n.7, p.1331-1342, 2000. 
NOLDT, G.; BAUCH, J.; SCHMITT, K.; BALODIS, V. G.; Structure of primary roots of Swietenia macrophylla King. under controlled conditions. BFH Mitteilungen, v.193, p.107-112, 1999.

OLIVEIRA, V.P.; MAFRA, M.V.P.; SOARES, A.P.A. Eventos climáticos extremos na Amazônia e suas implicações no município de Manaquiri (AM).

Revista Geonorte, v.1, n.5, p.977-987, 2012.

PUMIJUMNONG, N.; ECKSTEIN, D.; SASS, U. Tree-ring research on Tectona grandis in Northern Thailand. IAWA Journal, v.16, p.385-392, 1995.

SAEG Sistema para Análises Estatísticas. Versão 9.1. Viçosa, MG: Fundação Arthur Bernardes/UFV, 2007.

SCHMIDHALTER, U. The gradient between predawn rhizoplane and bulk soil matric potentials, and its relation to the pre-dawn root and leaf water potentials of four species. Plant, Cell and Environment, v.20, p.953-960, 1997.

SILVA, E.C.; NOGUEIRA, R. J. M. C.; AZEVEDO NETO, A. D.; SANTOS, V. F. Comportamento estomático e potencial da água da folha em três espécies lenhosas cultivadas sob estresse hídrico.

Acta Botanica Brasilica, v. 17, n.2, p.231-246, 2003.

SOUSA, S.G.A.; COSTA, J. R.; WANDELLI, E. V.; PERIN, R.; PEREIRA, S. M. Mogno (Swietenia macrophylla King) em um sistema agroflorestal estabelecido em áreas de pastagens degradadas na Amazônia Ocidental. In: Anais do VI

Simpósio Nacional e Congresso Latino - Americano de Recuperação de Áreas Degradadas, Curitiba: 2005. p.559-560.

Suguio, N. Mudanças ambientais da terra. São Paulo: Instituto Geológico, 2008. 336p.

SWAEF, T.D.; STEPPE, K.; LEMEUR, R.

Determining reference values for stem water potential and maximum daily trunk shrinkage in young apple trees based on plant responses to water deficit. Agricultural Water Management, v.9, n.6, p.541-550, 2009.

TAIZ, Z.; ZEIGER, E. Plant physiology. Sunderland: Sinauer Associates, 2004. 792p.

TEIXEIRA, L.B.; BASTOS, J.B. Nutrientes nos solos de Floresta Primária e pastagem de Brachiaria humidicola na Amazônia Central. Boletim de Pesquisa, Embrapa/ CPATU, n.98, p.1-311, 1989.

VETTER, R.E.; BOTOSSO, P.C. Remarks on age and growth-rate determination of Amazonian trees. IAWA Journal, v. 10, n.1, p.133-145, 1989.

VIGOUROUX, A.; BUSSI, C.; BERGER, J.F. Importance of water consumption for calcium nutrition of trees. Annales des Science Forestieres, v.46, p.396-371, 1989.

WILLIAMS, L.E.; ARAUJO, F.J. Correlations among predawn leaf, midday leaf, and midday stem water potential and their correlations with other measures of soil and plant water status in Vitis vinifera. Journal of the America Society for Horticulture and Science, v.127, n.3, p.448-454, 2002.

WORBES, M. Variety in structure of annual growth zones in Tabebuia barbata (E. Mey) Sandw. Bignoniaceae, a tropical tree species from Central Amazonian inundation forest. Dendrocronologia, v.6, n.1, p.7-89, 1988.

YARED, J.A.G.; CARPANEZZI, A.A. Conversão

de capoeira alta da Amazônia em povoamento de produção madeireira: o método do "recru" e espécies promissoras. Belém: Empresa Brasileira de Pesquisa Agropecuária/Centro de Pesquisa Agropecuária do Trópico Úmido. 1981. v.27. (Boletim de Pesquisa, 25). 